\title{
AS POLÍTICAS PÚBLICAS DE SEGURANÇA NA PANDEMIA CAUSADA PELA COVID-19
}

\author{
PUBLIC SAFETY POLICIES IN THE PANDEMIC CAUSED BY COVID-19
}

\author{
Washington Carlos de Almeida ${ }^{\mathrm{I}}$ \\ Washington Carlos de Almeida Júnior ${ }^{\text {II }}$
}

\footnotetext{
${ }^{\mathrm{I}}$ Universidade Presbiteriana Mackenzie, São Paulo, SP, Brasil. Doutor em Direito. E-mail: wcarlo-salmeida@uol.com.br

II Universidade Presbiteriana Mackenzie, São Paulo, SP, Brasil. Graduado em Direito. E-mail: prof.washington@uol. com.br
}

Resumo:Opresenteartigotrazumareflexãosobreas necessárias políticas de segurança pública a serem implementadas durante a pandemia ocasionada pela Covid-19, que alterou as condiçôes socioeconômicas da população em um país onde a desigualdade social é enorme e o sistema prisional deficiente, levando-se, ainda, em consideraçáo o crucial papel dos agentes de segurança pública na fiscalização das medidas de isolamento social, distanciamento social e lockdown. Serão abordadas algumas ações que estão sendo implementadas, e que merecem especial atenção das autoridades, no que diz respeito à segurança pública. $\mathrm{Na}$ metodologia empregada foi utilizado o método exegético, com análise de doutrina e dados de domínio público.

Palavras-chave: Políticas de segurança. Pandemia. Medidas de isolamento social.

\begin{abstract}
This article reflects on the necessary public security policies to be implemented during the pandemic caused by Covid-19, which changed the socioeconomic conditions of the population in a country where social inequality is enormous and the prison system deficient, leading to, also, taking into account the crucial role of public security agents in overseeing measures of social isolation, social distancing and lockdown. Some actions that are being implemented will be addressed, and that deserve special attention from the authorities, with regard to public safety. In the methodology used, the exegetical method was used, with analysis of doctrine and public domain data.
\end{abstract}

Keywords: Security policies. Pandemic. Social isolation measures. 


\section{Introdução}
A pandemia da COVID-19 alterou substancialmente as dinâmicas socioeconômicas e representa um enorme risco à saúde pública no Brasil e no mundo.

Levando em consideração que o Brasil é um país caracterizado pela imensa desigualdade social, no qual temos amplos segmentos da comunidade vivendo abaixo da linha da pobreza, e, ainda, em comunidades densamente povoadas, sem infraestrutura básica de saneamento e saúde, com altos índices de criminalidade, a segurança pública é uma enorme preocupação que não pode ser de maneira alguma negligenciada.

É crucial a adoção de políticas públicas que protejam, inclusive, os agentes de segurança pública, pois os agentes policiais têm por escopo cuidar para que as medidas de isolamento social, distanciamento social, quarentena e eventuais lockdown ${ }^{1}$ sejam cumpridas pela população em geral.

Além disso, temos que o desemprego ${ }^{2}$ e o impacto econômico ${ }^{3}$ ocasionados pela pandemia certamente levam ao aumento da violência, inclusive a doméstica, além do impacto sobre o sistema prisional brasileiro, superlotados e insalubres, que dificultam a contenção da pandemia e a adoção de medidas sanitárias eficientes de combate ao coronavírus.

No presente artigo, abordaremos algumas ações de segurança pública que estão sendo implementadas, e que merecem especial atenção das autoridades, no que diz respeito à segurança pública.

A segurança pública pode ser definida como um meio para que o Estado garanta o direito fundamental dos cidadáos de viverem em sociedade de forma pacífica ${ }^{4}$. Para atingir e alcançar esses direitos, o Estado presta serviços e elabora políticas públicas com essa finalidade.

Segundo o art. 144 da Constituição Federal5, "a segurança pública, dever do Estado, direito e responsabilidade de todos, é exercida para a preservação da ordem pública e da incolumidade das pessoas e do patrimônio...”.

1 Importante aqui destacar a diferença entre isolamento, distanciamento social, quarentena e lockdown. O distanciamento social busca, de forma voluntária, restringir a aproximaçáo entre as pessoas como forma de controlar a disseminação da doença; o isolamento social também é uma medida náo obrigatória para evitar a propagação do vírus, que serve para separar pessoas sintomáticas ou assintomáticas, que foram contaminadas ou estão com suspeita e, a depender da situação, os pacientes podem ficar isolados em ambiente domiciliar ou em hospitais; a quarentena restringe o acesso ou circulação de pessoas que foram ou podem ter sido expostas ao vírus; já o lockdown é uma paralisação total dos fluxos e deslocamentos. A circulação de carros e pessoas também é reduzida, sendo autorizada apenas a saída de casa para a compra de alimentos, medicamentos e transporte de indivíduos para hospitais.

2 Hoje, são cerca de 12.850 milhóes de brasileiros sem trabalho, o que representa 1 milhão e 200 mil pessoas a mais na fila do emprego.

3 A pandemia provocada pelo novo coronavírus fará a economia brasileira encolher 5,2\% neste ano, prevê a Comissão Econômica para a América Latina e o Caribe (Cepal). Segundo o órgão, vinculado à Organização das Naçóes Unidas (ONU), a América Latina sofrerá a pior crise social em décadas, com milhóes de pessoas passando por desemprego e pobreza. Fonte: JORNAL DO COMÉRCIO. Economia do Brasil encolherá 5,2\% por causa de pandemia de coronavírus prevê Cepal. Disponível em: https://www.jornaldocomercio. com/_conteudo/economia/2020/04/735421-economia-do-brasil-encolhera-5-2-por-causa-de-pandemia-decoronavirus-preve-cepal.html. Acesso em 30 de maio de 2020.

4 RODRIGUES, João Gaspar. Segurança Pública e comunidade: alternativas à crise. Porto Alegre: Sergio Antonio Fabris Editor, 2009.

5 BRASIL. Constituiçáo Federal. Disponível em https://www.senado.leg.br/atividade/const/con1988/ 
A política de segurança pública, portanto, consiste nas decisóes públicas que visam estabelecer a paz social por meio da definição de objetivos e estratégias de atuação e de alocação dos recursos públicos.

A repartição de competências para legislar sobre matérias relacionadas à segurança pública pode ser classificada em dois grupos. No primeiro grupo, estáo as normas jurídicas que, em seu conjunto, definem o direito penal e processual penal e a correspondente política criminal. No Brasil, os principais aspectos da política criminal são definidos pelo Congresso Nacional. Cabe ao parlamento nacional a definição de condutas criminosas, bem como a majoração ou a redução de penas, bem como sua extinção. No segundo grupo, estão as normas jurídicas que regulamentam a organização da política de segurança pública e penitenciária, ou seja, os elementos que estruturam a execução da política criminal e da execução penal, mas que não adentram na definição dos tipos penais e, tampouco, nas normas de direito processual penal.

Já em relação à execução da política de segurança pública, há repartição de competências entre a União e os estados. O sistema policial brasileiro rege-se pelo disposto no art. 144 do texto constitucional, que estabelece que a segurança pública será exercida por meio dos seguintes órgãos:

I - Polícia Federal;

II - Polícia Rodoviária Federal;

III - Polícia Ferroviária Federal;

IV - Polícias Civis;

V - Polícias Militares e Corpos de Bombeiros Militares.

VI - Polícias Penais Federal, Estaduais e Distrital.

Com base nesse dispositivo da Constituição Federal, conclui-se que o sistema policial brasileiro é formado, basicamente, por entidades federais de competências específicas e por instituiçóes estaduais de competência geral — judiciária (Polícia Civil) e ostensiva (Polícia Militar). Aos municípios faculta-se a possibilidade de constituir guardas municipais, com vistas à proteção de seus próprios bens, serviços e instalações.

A segurança pública conta com as Polícias Civil e Militar nas atividades de prevenção e repressão à criminalidade, tendo cada uma delas uma função específica. A Polícia Militar é responsável pelo policiamento preventivo, executando a ronda ostensiva em todas as suas modalidades e atuando na manutenção e restauração da ordem de uma forma geral. Já a Polícia Civil é responsável pela investigação e instrução processual dos crimes praticados no território estadual.

Por fim, no âmbito municipal, as prefeituras brasileiras têm ampliado seu papel em atividades de prevenção à criminalidade, seja por meio da criação de guardas municipais seja por intermédio de políticas sociais e urbanísticas voltadas para áreas de maior incidência criminal.

$\mathrm{Na}$ interpretação da norma constitucional disposta no art. 144 da Carta magna, o Supremo Tribunal Federal já teve a oportunidade de se manifestar sobre o tema no RE 559.646$\mathrm{AgR}^{6}$, afirmando que o direito a segurança é prerrogativa constitucional indisponível, a qual 
deve ser implementada por meio de políticas públicas, obrigando ao Estado produzir condiçóes objetivas, de tal modo que possibilite o acesso do cidadão a este serviço público. Assim, muito embora esta atribuição e comando parta da iniciativa do Poder Executivo, nada impede que o Poder Judiciário determine implementaçôes de políticas públicas constitucionalmente previstas, isto é, quando o Estado (Poder Executivo) se mostrar inoperante.

É extremamente importante, nessa época em que vivemos a maior pandemia mundial dos últimos tempos, a adoção de políticas públicas voltadas à segurança pública, relativas tanto à população quanto voltadas aos agentes de segurança pública.

\section{Algumas políticas públicas que vêm sendo adotadas pelo governo brasileiro}

Dentre as necessárias políticas públicas de segurança, decorrentes da pandemia que estamos vivendo, apontaremos algumas já em efetivação.

\subsection{Garantia de equipamentos de proteção individual (EPIs)}

A primeira preocupação no que diz respeito à segurança pública é a proteção dos profissionais da segurança pública e do sistema prisional com a garantia de equipamentos individuais (EPIs).

Assim, uma importante política é assegurar as condiçôes sanitárias e de higiene desses atores, implementando protocolos de ação para diminuição dos riscos de contágio e planos de contingência, como por exemplo, fornecimento de máscaras, álcool em gel, higienização de viaturas e unidades policiais.

Como se trata de uma pandemia que atingiu o mundo todo, os direitos humanos, ditam regras de que o Estado nação lidera o crescente processo de bem-estar econômico e social dos cidadãos por meio da cooperação internacional e solidariedade, ${ }^{7}$ ou seja, cabe ao Estado zelar pela preservação tanto da economia como do bem-estar da nação.

Há projeto de lei tramitando (PL 1409/20) ${ }^{8}$, de autoria dos Deputados Dr. Zacharias Calil (DEM-GO) e outros, que: "Determina que em caso de declaração de epidemia, pandemia ou surtos provocados por doenças contagiosas ou que tenha sido declarado Estado de Calamidade Pública sejam tomadas medidas imediatas que garantam a saúde e preservação da vida de todos profissionais considerados essenciais ao controle de doenças e manutenção da ordem pública”, tramitando em regime de urgência, atualmente guardando Designação de Relator na Comissão de Trabalho, de Administração e Serviço Público (CTASP), pois sofreu alterações do Senado e retornou à Câmara dos Deputados.

A lista dos profissionais considerados essenciais ao controle de doenças e à manutenção da ordem pública, no texto aprovado pela Câmara, já incluía várias categorias da área de saúde, como médicos, enfermeiros, farmacêuticos, fisioterapeutas, agentes e técnicos. Também já

a tal serviço." (STF - RE 559.646-AgR, rel. Min. Ellen Gracie, julgamento 07.06.2011, Segunda Turma, DJE de 24.06.2011).

7 RAJAGOPAL, Balakrishnan. "Direito ao Desenvolvimento e Governança Global: Velhos e Novos Desafios Vinte e Cinco Anos Depois.” Direitos Humanos Trimestral 35, no 42013.

8 PL 1409/2020. Disponível em: https://www.camara.leg.br/proposicoesWeb/ fichadetramitacao?idProposicao=2242681. Acesso em 30 de maio de 2020 . 
estavam na lista trabalhadores de serviços funerários, policiais, membros das Forças Armadas, guardas municipais e profissionais de limpeza, entre outros.

No Senado, esse rol foi ampliado e passou a contar com outras categorias, como brigadistas, agentes penitenciários, técnicos e auxiliares em saúde bucal, veterinários, trabalhadores do setor aéreo, controladores de voo e profissionais de centros de assistência social. Também foram incluídos e servidores públicos que trabalham na área da saúde, inclusive em funçóes administrativas, e trabalhadores da cadeia de produção de alimentos e bebidas. ${ }^{9}$

\subsection{Utilização de protocolos e tecnologias que garantam a proteção dos profissionais}

Algumas medidas, como a de facilitar registros de crimes pela internet ${ }^{10}$; diminuir profissionais em atendimento ao público; criar escalas que considerem o ritmo de infecção e afastamento desses profissionais por COVID-19, entre outros, estáo sendo observadas, inclusive estabelecendo protocolos de prioridade do trabalho considerando a possibilidade de atividades em teletrabalho ${ }^{11}$.

\subsection{Acesso à saúde}

Importantíssimo o estabelecimento de políticas públicas voltadas à estrutura de hospitais dedicados aos agentes de segurança pública, priorizando a testagem para a Covid-19, garantindo o cuidado à saúde dos agentes e seus familiares e assegurando a testagem prioritária dessas categorias.

Em São Paulo foi adotada a política de testagem prioritária dos agentes da polícia militar e, após ação proposta pela ADPESP (Associação dos Delegados de Política de São Paulo), foi estendida aos policiais civis ${ }^{12}$.

\subsection{Monitoramento e reorientação do trabalho das forças de segurança para lidar com os novos problemas de segurança}

Fornecer condições de trabalho das forças de segurança, inclusive com a colaboração de agentes em nível municipal, estadual e federal, é política necessária e crucial, inclusive com a adoção de diversas medidas, dentre as quais podemos destacar:

a) monitoramento contínuo da situaçáo e definição de atuação rápida para lidar com as emergências e identificar novas dinâmicas criminais;

b) dar prioridade ao enfrentamento de crimes violentos;

9 Fonte: Agência Senado.

10 O sistema da Polícia Civil do Estado de São Paulo admitiu registrar pela internet a quase totalidade das ocorrências policiais. A única exceção são ocorrências que dependem de coleta imediata de provas, como homicídios, latrocínios, estupros.

11 Em São Paulo, o teletrabalho foi instituído pela Portaria DGP no 16, de 17/03.2020. Disponível em https:// www.defensoria.sp.def.br/dpesp/Repositorio/41/Documentos/DDM\%20-\%20PORTARIA\%20DGP\%20 CORONA.pdf.pdf. Acesso em 30 de maio de 2020.

12 DALL'AGNOL. Delegados de SP vão à Justiça por testes para Covid-19. Disponível: https://agora.folha. uol.com.br/grana/2020/05/delegados-de-sp-vao-a-justica-por-testes-para-covid-19.shtml. Acesso em 29 de maio de 2020. 
c) planejar com antecedência o atendimento de novas demandas (escoltas de produtos sensíveis como medicamentos, equipamentos de proteção, etc.);

d) reorganizar os protocolos e programas de policiamento a partir das novas dinâmicas criminais observadas após medidas de isolamento social (violência doméstica, roubos de insumos hospitalares etc.);

e) elaborar e implementar protocolos operacionais para açóes de fiscalização do distanciamento social/quarentena, controle de convulsão social, etc.; e,

f) repensar as ações relacionadas ao patrulhamento ostensivo de comunidades pobres e densamente povoadas, com vistas a reduzir potenciais açôes letais. ${ }^{13}$

\subsection{Açöes contra a violência doméstica e familiar}

Em tempos de isolamento social verifica-se um considerável aumento na violência doméstica e familiar, sendo necessária a adoçáo de políticas públicas para o enfrentamento dessa situação, como, por exemplo, a possibilidade de registro de ocorrências de violência doméstica pela internet, bem como, a criação de redes de apoio e campanhas e serviços de acolhimento para as mulheres, crianças e adolescentes vítimas.

Segundo um levantamento realizado pelo Fórum Brasileiro de Segurança Pública (FBSP), o número de ocorrências de violência contra a mulher aumentou em seis estados (São Paulo, Acre, Rio Grande do Norte, Rio Grande do Sul, Mato Grosso e Pará), em comparação ao mesmo período em 2019.

Só no Estado de São Paulo, onde a quarentena foi adotada no dia 24 de março de 2020, a Polícia Militar registrou um aumento de 44,9\% no atendimento a mulheres vítimas de violência, o total de socorros prestados passou de 6.775 para 9.817. Casos de feminicídios também subiram, de 13 para 19 (46,2\%).

De acordo com dados do Ligue 180 - canal gratuito para denúncias de violência contra a mulher - em abril houve aumento de 36\% no número de denúncias em relação ao mesmo mês em $2019^{14}$.

Conforme se verifica no gráfico abaixo, em abril de 2019 houve 7.243 denúncias, ao passo que, em abril de 2020, o número de denúncias de violência doméstica saltou para $9.842^{15}$ :

13 INSTITUTO SOU DA PAZ. Especialistas Elaboram 10 Medidas Para A Segurança Pública Durante A Pandemia Da Covid -19. Disponível em http://soudapaz.org/noticias/especialistas-elaboram-10-medidaspara-a-seguranca-publica-durante-a-pandemia-da-covid-19/\#_ftn2. Acesso em 26 de maio de 2020.

14 RODRIGUES, Alex. Ligue 180 registra aumento de $36 \%$ em casos de violência contra mulher. Disponível em: https://agenciabrasil.ebc.com.br/geral/noticia/2020-05/ligue-180-registra-aumento-de-36-em-casos-deviolencia-contra-mulher. Acesso em 30 de maio de 2020.

15 RODRIGUES, Alex. Ligue 180 registra aumento de $\mathbf{3 6} \%$ em casos de violência contra mulher. Disponível em: https://agenciabrasil.ebc.com.br/geral/noticia/2020-05/ligue-180-registra-aumento-de-36-em-casos-deviolencia-contra-mulher. Acesso em 30 de maio de 2020. 


\section{COMPARATIVO DE DENÚNCIAS NO 10 QUADRIMESTRE DE 2020}

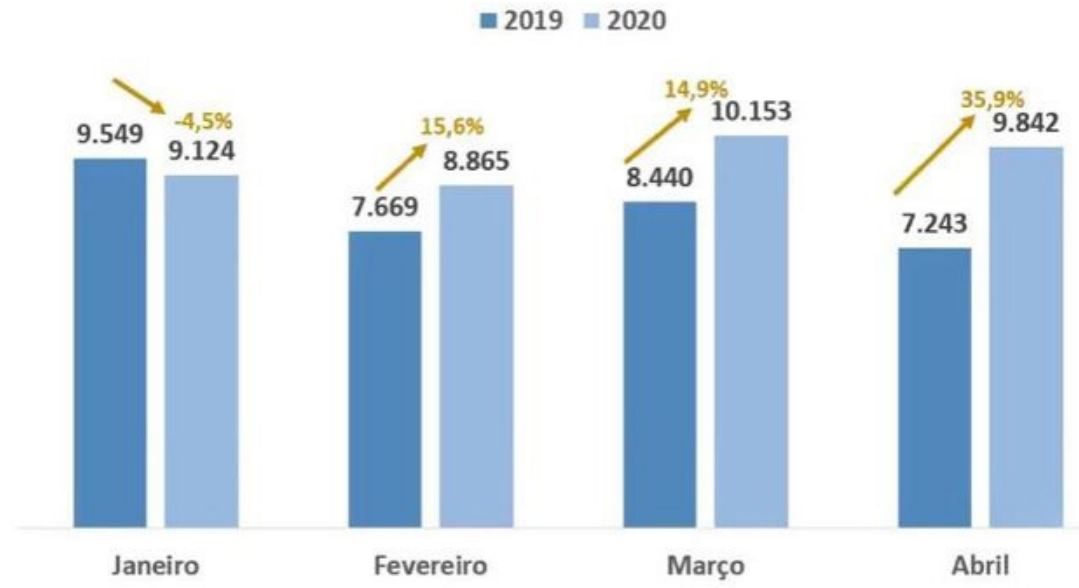

Hoje, o Brasil ocupa a quinta posição de país com a maior taxa de feminicídio do mundo. A cada duas horas uma mulher é assassinada no país. A maioria delas foi morta por seus companheiros ou por parentes próximos.

O Brasil apresentou algumas medidas para tentar conter os índices de violência e feminicídio (homicídio de mulher motivado por violência doméstica ou discriminação de gênero). Alguns estados, como o de São Paulo, Rio de Janeiro, Espírito Santo e o Distrito Federal anteciparam a ampliação de seus serviços da delegacia eletrônica e disponibilizaram o registro online de boletins de ocorrências de violência doméstica.

O governo federal também determinou a criação de um aplicativo, o "Direitos Humanos BR"16, uma ferramenta para denunciar diversas violaçôes.

\subsection{Recomendação CNJ 62/202017 do Conselho Nacional de Justiça}

Importante destacar as recomendações da Resolução CNJ 62/2020 como política a ser seguida, realizando mutirôes do poder judiciário para revisão das penas privativas de liberdade e das prisóes provisórias, com vistas a diminuir a superlotação de presídios e, dessa maneira, a taxa de contágio por COVID-19, reavaliando prisóes provisórias, de grupos vulneráveis e prisóes preventivas com prazo superior a 90 (noventa) dias ou que resultem de crimes menos graves, assim como o habeas corpus coletivo concedido para grávidas e mães de crianças de até 12 (doze) anos pelo Supremo Tribunal Federal em fevereiro de 2018.

De acordo com artigo publicado pela Friedrich-Ebert-Stiftung Brasil, em 17 de março, o CNJ (Conselho Nacional de Justiça) aprovou e divulgou a Resolução n. 62, com

16 MINISTÉRIO DA MULHER, DA FAMÍLIA E DOS DIREITOS HUMANOS. Aplicativo de denúncias de violaçáo de direitos humanos já está disponível. Disponível em: https:/www.gov.br/mdh/pt-br/assuntos/ noticias/2020-2/abril/aplicativo-de-denuncias-de-violacao-de-direitos-humanos-ja-esta-disponivel. Acesso em 30 de maio de 2020

17 CONSELHO NACIONAL DA JUSTIÇA. Disponível em: https://www.cnj.jus.br/wp-content/ uploads/2020/03/62-Recomenda\%C3\%A7\%C3\%A3o.pdf. Acesso em 26 de maio de 2020. 
recomendaçóes para a redução da população carcerária para conter a disseminação do novo coronavírus no sistema prisional brasileiro. Poucos dias antes, entidades de direitos humanos haviam demandado e entrado com liminar no Supremo Tribunal Federal para que medidas alternativas fossem tomadas no sentido de prevenir a exposição de presos ao vírus. Ainda em 17 de março, o ministro Marco Aurélio Mello fez um conclame a juízes de execução penal brasileiros e sugeriu uma série de medidas preventivas a fim de evitar o avanço da doença nos presídios, citando a "situação precária e desumana dos presídios e penitenciárias" do país. Dentre as providências sugeridas, temos:

a) a liberdade condicional para presos com idade igual ou superior a 60 anos;

b) o regime domiciliar para presos entre os grupos de risco, como soropositivos, diabéticos, com doenças cardíacas, tuberculose, etc.;

c) o regime domiciliar para gestantes e lactantes;

d) o regime domiciliar para presos que cometeram crimes sem violência ou grave ameaça;

e) a substituição da prisão provisória por medidas alternativas para delitos praticados sem violência ou grave ameaça; etc.

Em 18 de março, o plenário do STF rejeitou as medidas emergenciais sugeridas pelo ministro Marco Aurélio Mello e a maioria da corte seguiu voto do ministro Alexandre de Moraes, compreendendo que as recomendaçôes do CNJ já seriam suficientes. É de se concordar com o comentário do ministro Marco Aurélio Mello de que as medidas por ele indicadas eram nada mais do que óbvias diante do cenário pandêmico, observando as medidas sendo adotadas e orientadas pelo Ministério da Saúde.

As prisôes do país encontram-se, em sua grande maioria, superlotadas, o que aumenta a vulnerabilidade da população carcerária. É importante levar em consideração os outros problemas de saúde aos quais essa populaçáo já está exposta, seja pelas condiçóes precárias das unidades prisionais ou pela deficiência na assistência. No caso de transmissão do vírus dentro das unidades prisionais, o grau de infecção é grande, não sendo possível que o sistema de saúde absorva essa grande demanda, gerando um caos no sistema penitenciário. ${ }^{18}$

Em São Paulo, algumas açôes têm sido implementadas pela Secretaria da Administração Penitenciária, que vem adotando medidas de higiene, distanciamento social, proibição de visitas, vacinação e prevenção da doença, entre outras. ${ }^{19}$

No entanto, essas medidas adotadas pelo Governo estadual de São Paulo não têm alcançado os objetivos almejados e, segundo notícias recentes, o número de infectados no sistema prisional paulista aumentou $35 \%$ (trinta e cinco por cento) ${ }^{20}$.

18 BORGES, Juliana. O que a pandemia do coronavírus expóe sobre as prisóes? Disponível em https://www. fes-brasil.org/detalhe/o-que-a-pandemia-do-coronavirus-expoe-sobre-as-prisoes/. Acesso em 28 de maio de 2020.

19 http://www.sap.sp.gov.br/ . Acesso em 30 de maio de 2020.

20 PAGNAN, Rogério. Coronavírus avança e 35\% de presídios de SP têm casos suspeitos ou confirmados. Disponível: https://www1.folha.uol.com.br/cotidiano/2020/05/coronavirus-avanca-e-35-de-presidios-de-sptem-casos-suspeitos-ou-confirmados.shtml. Acesso em 30 de maio de 2020. 
O SIFUPESP (Sindicato dos Funcionários do Sistema Prisional do Estado de Sáo Paulo) denunciou, recentemente, que faltam EPIs, álcool em gel e outros itens de limpeza para prevenção do contágio ${ }^{21}$.

\subsection{Segurança física e mental dos agentes de segurança pública}

Por fim, e não menos importante, é o estabelecimento de políticas públicas que garantam não apenas a segurança física, mas a saúde mental dos agentes de segurança pública.

De acordo com RACORTI e REIS, “cabe aos dirigentes da polícia reconhecer o cansaço mental que esse evento de saúde pública impóe a seus policiais, sendo de fundamental importância que os centros de apoio psicoemocional sustentem os esforços dos agentes da lei durante o prazo que perdurar o incidente". E prosseguem asseverando que "o cansaço mental é uma preocupação tão grande quanto a própria contaminaçấo com o vírus" 22 .

Com efeito, existe o risco de, em situação de colapso do sistema de saúde e da economia, ocorrerem casos de verdadeira estafa mental por parte não só da população, como dos agentes de segurança.

Portanto, além dos cuidados de higiene e saúde desses agentes, é importante adotar políticas que objetivem cuidar também da saúde mental desses profissionais.

Não podemos olvidar, ainda, que se não forem implementadas políticas públicas para proteção da saúde física e mental dos agentes de segurança pública, ocorrerá colapso não somente do sistema de saúde (falta de leitos, UTIs, respiradores e equipamentos para a população doente), mas, em havendo diminuição do efetivo decorrente da contaminação e aumento do número de pessoas que necessitarão de maior atuação da polícia haverá, certamente, uma crise de segurança pública assolando o país.

\section{Conclusóes}

As forças de segurança pública no Brasil são importantíssimas para o combate à pandemia da COVID-19, pois serão os agentes de segurança que garantirão a aplicação da lei e a ordem caso haja colapso do sistema de saúde e desespero da sociedade como um todo.

Sabemos que essas forças nunca tiveram a devida valorização no país e, ainda, é óbvio que se houver um colapso do sistema de saúde, sendo que, se houver um significativo aumento dos índices de contaminação pela COVID-19, haverá, consequentemente, um colapso em nossas forças de segurança pública.

Igualmente, é cediço que o Brasil possui a terceira maior população carcerária do mundo e nossos presídios são, em sua maioria, superlotados. Isso sem contar que a maioria da polpação carcerária é composta por jovens, carentes, pardos e negros, de origem humilde, a maioria

21 AGÊNCIA BRASIL. Ao menos 41 unidades prisionais de São Paulo tem casos de coronavírus. Disponível em: https://agenciabrasil.ebc.com.br/saude/noticia/2020-05/ao-menos-41-unidades-prisionais-de-sao-paulo-temcasos-de-coronavirus. Acesso em 30 de maio de 2020.

22 RACORTI, Valmor Saraiva; REIS, Wellington. Aplicação da lei pelas forças de segurança diante do CoVid-19. Disponível em http://www.defesanet.com.br/pw/noticia/36181/Aplicacao-da-lei-pelas-forcas-deseguranca-diante-do-CoVid-19/. Acesso em 30 de maio de 2020. 
processada por crimes contra o patrimônio e pela lei de drogas e sem condenaçáo definitiva ou transitada em julgado.

Portanto, adotar políticas de segurança pública eficazes, como as medidas de higiene, medidas visando assegurar a saúde física e mental dos agentes de segurança e de seus familiares, bem como medidas eficazes para assegurar EPIs e equipamentos adequados e a correta higiene das dependências policiais e presídios, assegurando-se, ainda, a saúde da população carcerária e respectivos familiares, é fundamental para o combate à pandemia. Igualmente importante a adoção de políticas de controle da população carcerária, assim como políticas para um eficaz atendimento às vítimas de violência nesse período de pandemia, inclusive às vítimas de violência doméstica e familiar, que têm aumentado consideravelmente com as medidas de distanciamento social, isolamento social, quarentena e lockdown.

Como vimos acima, várias políticas vêm sendo adotadas em nível federal, estadual e municipal, algumas eficazes, outras que ainda são objeto de críticas e denúncias pela ausência de efetividade.

Urge que as autoridades governamentais adotem essas políticas e destinem recursos suficientes para que as mesmas sejam efetivadas e tenham a eficácia almejada, a fim de evitarmos não somente a crise econômica e o colapso do sistema de saúde, mas, também, o colapso da segurança pública de nosso país.

\section{Referências}

AGÊNCIA BRASIL. Ao menos 41 unidades prisionais de São Paulo tem casos de coronavírus. Disponível em: https://agenciabrasil.ebc.com.br/saude/noticia/2020-05/ao-menos-41unidades-prisionais-de-sao-paulo-tem-casos-de-coronavirus Acesso em 30 de maio de 2020.

BORGES, Juliana. O que a pandemia do coronavírus expóe sobre as prisóes? Disponível em: https://www.fes-brasil.org/detalhe/o-que-a-pandemia-do-coronavirus-expoe-sobre-asprisoes/. Acesso em 28 de maio de 2020.

BRASIL. Constituição Federal. Disponível em https://www.senado.leg.br/atividade/const/ con1988/con1988_atual/art_144_.asp. Acesso em 26 de maio de 2020.

CONSELHO NACIONAL DA JUSTIÇA. Disponível em: https:/www.cnj.jus.br/wpcontent/uploads/2020/03/62-Recomenda\%C3\%A7\%C3\%A3o.pdf. Acesso em 26 de maio de 2020.

DALL'AGNOL. Delegados de SP váo à Justiça por testes para Covid-19. Disponível: https://agora.folha.uol.com.br/grana/2020/05/delegados-de-sp-vao-a-justica-por-testes-paracovid-19.shtml. Acesso em 29 de maio de 2020.

\section{INSTITUTO SOU DA PAZ. Especialistas Elaboram 10 Medidas Para A Segurança}

Pública Durante A Pandemia Da Covid -19. Disponível em http://soudapaz.org/noticias/ especialistas-elaboram-10-medidas-para-a-seguranca-publica-durante-a-pandemia-dacovid-19/\#_ftn2. Acesso em 26 de maio de 2020. 
JORNAL DO COMÉRCIO. Economia do Brasil encolherá 5,2\% por causa de pandemia de coronavírus prevê Cepal. Disponível em: https://www.jornaldocomercio.com/_conteudo/ economia/2020/04/735421-economia-do-brasil-encolhera-5-2-por-causa-de-pandemia-decoronavirus-preve-cepal.html. Acesso em 30 de maio de 2020.

MINISTÉRIO DA MULHER, DA FAMÍLIA E DOS DIREITOS HUMANOS. Aplicativo de denúncias de violação de direitos humanos já está disponível. Disponível em: https:// www.gov.br/mdh/pt-br/assuntos/noticias/2020-2/abril/aplicativo-de-denuncias-de-violacao-dedireitos-humanos-ja-esta-disponivel. Acesso em 30 de maio de 2020.

PAGNAN, Rogério. Coronavírus avança e 35\% de presídios de SP têm casos suspeitos ou confirmados. Disponível: https://www1.folha.uol.com.br/cotidiano/2020/05/coronavirusavanca-e-35-de-presidios-de-sp-tem-casos-suspeitos-ou-confirmados.shtml Acesso em 30 de maio de 2020.

PL 1409/2020. Disponível em: https://www.camara.leg.br/proposicoesWeb/ fichadetramitacao?idProposicao=2242681. Acesso em 30 de maio de 2020.

Portaria DGP no 16, de 17/03.2020. Disponível em https:/www.defensoria.sp.def.br/dpesp/ Repositorio/41/Documentos/DDM\%20-\%20PORTARIA\%20DGP\%20CORONA.pdf.pdf. Acesso em 30 de maio de 2020.

RACORTI, Valmor Saraiva; REIS, Wellington. Aplicação da lei pelas forças de segurança diante do CoVid-19. Disponível em https://www.defesanet.com.br/pw/noticia/36181/ Aplicacao-da-lei-pelas-forcas-de-seguranca-diante-do-CoVid-19. Acesso em 30 de maio de 2020.

RAJAGOPAL, Balakrishnan. "Direito ao Desenvolvimento e Governança Global: Velhos e Novos Desafios Vinte e Cinco Anos Depois.” Direitos Humanos Trimestral 35, no 42013.

RODRIGUES, Alex. Ligue 180 registra aumento de $36 \%$ em casos de violência contra mulher. Disponível em: https://agenciabrasil.ebc.com.br/geral/noticia/2020-05/ligue-180registra-aumento-de-36-em-casos-de-violencia-contra-mulher. Acesso em 30 de maio de 2020.

RODRIGUES, João Gaspar. Segurança Pública e comunidade: alternativas à crise. Porto Alegre: Sergio Antonio Fabris Editor, 2009. 